Boise State University ScholarWorks

Public Policy and Administration Faculty

Publications and Presentations

Department of Public Policy and Administration

6-1-2013

\title{
Indian Gaming and Tribal Revenue Allocation Plans: Socio-Economic Determinants of Policy Adoption
}

Thaddieus W. Conner

Boise State University

William A. Taggart

New Mexico State University

This is the author's version of a work that was accepted for publication in The Social Science Journal. Changes resulting from the publishing process, such as peer review, editing, corrections, structural formatting, and other quality control mechanisms may not be reflected in this document. Changes may have been made to this work since it was submitted for publication. A definitive version was subsequently published in The Social Science Journal 50(2), 162-167. DOI: 10.1016/j.soscij.2013.01.002 


\title{
Indian Gaming and Tribal Revenue Allocation Plans: Socio-Economic Determinants of Policy Adoption*
}

\author{
Thaddieus W. Conner \\ Boise State University \\ William A. Taggart \\ New Mexico State University
}

\begin{abstract}
As the Indian gaming industry has experienced unprecedented growth over the past two decades, tribes have pursued different paths regarding the utilization of gaming revenues within parameters established by the Indian Gaming Regulatory Act. Since 1993, more than 100 tribes have received approval through the Department of the Interior to distribute revenues directly to tribal members through per capita payments governed by a Tribal Revenue Allocation Plan (RAP). This paper seeks to improve our understanding of nations with payment plans by exploring whether socio-economic tribal features are associated with the successful adoption of a RAP. We find that tribes who gained approval of a RAP in the 1990s have relatively higher per capita incomes, while also having smaller populations and lower levels of educational attainment. Population is the strongest predictor of RAP adoptions in both the 1990s and 2000s, with the impact of other tribal features being less meaningful in explaining adoption in the second decade.
\end{abstract}

*Direct correspondence to Thaddieus W. Conner, Department of Public Policy and Administration, Environmental Research Building, Room 5147, Boise State University, Boise, ID, 83725, tadconner@boisestate.edu, (757)3509266. The first author will share all data and coding information for purposes of replication. An earlier version of this paper was presented at the 2011 annual meeting of the Southwest Social Science Association, Las Vegas, Nevada. The authors would like to acknowledge the Harvard Project on American Indian Economic Development for making the data used in this paper public and the U. S. Department of the Interior for providing a list of nations with Revenue Allocation Plans. 
This is the author's version of a work that was accepted for publication in The Social Science Journal. Changes resulting from the publishing process, such as peer review, editing, corrections, structural formatting, and other quality control mechanisms may not be reflected in this document. Changes may have been made to this work since it was submitted for publication. A definitive version was subsequently published in The Social Science Journal, available online 16 February 2013. DOI: 10.1016/j.soscij.2013.01.002

\section{Introduction}

The Indian gaming industry in the U.S. has experienced considerable growth since passage of the Indian Gaming Regulatory Act (IGRA) in 1988 (Schapp, 2010; Witmer and Boehmke, 2007). Virtually all of the 32 American states that are home to federally recognized tribes have at least one establishment offering gaming activities covered by IGRA provisions. By 2010, over 200 tribes representing approximately three-quarters of the nations in the lower 48 states operated more than 400 gaming facilities (Meister, 2010; Smith and Taggart, 2010). At the close of the 1980 s, a relatively small number of these tribes, offering bingo primarily, had estimated annual revenues under $\$ 250$ million (National Gambling Impact Study Commission [NGISC], 1999). Fast-forward 20 years, and Indian gaming is now generating revenues surpassing \$25 billion annually (National Indian Gaming Association [NIGA], 2011), representing a 44\% share of the American casino market (American Gaming Association [AGA], 2010).

These gaming nations have pursued vastly different paths regarding the utilization of their revenues within parameters established by the IGRA, reflecting the broad plenary power of Congress relative to matters related to American Indians (Light and Rand, 2005; Morse and Goss, 2007). The law stipulates five general categories of permissible uses, including supporting economic development, funding tribal government, donating to charitable organizations, helping local government agencies, and providing for the general welfare of tribal members (IGRA, 1988). In addition, under certain conditions the IGRA [Section 2710(d)(1)(a)(ii)] permits a nation to distribute per capita payments to tribal members. The Department of the Interior, through the Bureau of Indian Affairs (BIA), is responsible for approving a Tribal Revenue Allocation Plan or RAP before a tribe can engage in making payments (Department of Interior 25 C.F.R. 290). To gain RAP approval, a tribe must demonstrate an ability to meet the needs of members through investments in the aforementioned areas before making direct payments. This suggests Interior approval of a RAP is indicative of a tribe's ability to demonstrate compliance with this requirement to some level of satisfaction. Since 1993, more than 100 nations have received BIA approval to distribute revenues through per capita payments. ${ }^{1}$ These nations appear to have the resources to fund a mixture of mandated activities and intend to offer payments to tribal members. Beyond the occasional, typically sensationalized, media story (Bartlett and Steele, 2002) however, there is a dearth of knowledge concerning this aspect of Indian gaming (Taggart and Conner, 2011).

We argue that the economic and social conditions among RAP adopters are more favorable compared to nonadopters, putting them in a superior position to develop a convincing plan capable of securing Interior approval. The members of adopting nations, for instance, appear to have higher incomes, lower unemployment levels, and less poverty than other nations (Taggart and Conner, 2011). The possible existence of such relationships is consistent with long standing research underscoring the importance of favorable internal socio-economic conditions in shaping policy adoption, especially among early adopters or innovators (Berry and Berry, 2007; Gray, 1973). Innovators share a number of traits that distinguish them from later adopters, such as greater wealth (Grossback, NicholsonCrotty, and Peterson, 2004). More important have been studies looking at the adoption and diffusion of various types of gaming activities, which also report similar linkages (Berry and Berry, 1990; Furlong, 1998; Krepps, Taylor and Bucks, 1998; Winn and Whicker, 1990).

Research also suggests that demographic factors are important in understanding policy adoption generally and RAPs in particular (Taggart and Conner, 2011). Perhaps the most obvious consideration is the size of a nation. Smaller gaming tribes appear to be in a more advantageous position compared to larger nations in realizing the benefits of per capita payments (Rand and Light, 1997; Taggart and Conner, 2011). First, it is comparatively less expensive for smaller nations to address the distributional elements delineated in the IGRA and have revenues available for making payments to members. Second, a smaller number of members mean fewer funds are required for payments; individual payments that one assumes become significant rather quickly. A similarly situated but larger nation may decide against adopting a plan if the payments reflect minimal amounts, choosing instead to spend the funds in an alternative fashion. These considerations depend on a tribe's sense of what is a reasonable or meaningful threshold amount to have available before deciding to allocate their extra revenues through per capita payments; it is a decision rendered less complicated as the number of tribal members decline. 
This is the author's version of a work that was accepted for publication in The Social Science Journal. Changes resulting from the publishing process, such as peer review, editing, corrections, structural formatting, and other quality control mechanisms may not be reflected in this document. Changes may have been made to this work since it was submitted for publication. A definitive version was subsequently published in The Social Science Journal, available online 16 February 2013. DOI: 10.1016/j.soscij.2013.01.002

Finally, Rand and Light (1997) note that some raise the possibility that making payments to tribal members has negative consequences, including serving as a disincentive in the pursuit of educational opportunities. The implication is that making payments to individuals functions to diminish the perceived worth or value of education. This indicates there is a negative relationship between education and RAP adoptions, as tribes reflecting greater educational attainment, resist attempts to pay individuals directly and encourage other types of initiatives that benefit the tribe (Taggart and Conner, 2011).

This paper improves our understanding of nations with payment plans by exploring whether particular tribal features are associated with the approval of RAP adoptions. There are reasons to suspect that some gaming nations are comparatively more likely to have a payment plan based on the economic, demographic, and educational characteristics that vary across tribes. We expect that tribes with higher per capita incomes are more likely to have a RAP than less affluent gaming nations. We also posit that tribes with larger populations and greater educational achievement are comparatively less likely to have a RAP. After discussing the data and methods informing the investigation, we summarize the findings using multivariate logistic regression analysis.

\section{Data and Methods}

We utilize 1990 and 2000 tribal census data compiled by the Harvard Project on American Indian Economic Development (Taylor and Kalt, 2005) to examine RAP adoptions by gaming nations during the 1990s and 2000s representing two groups, or waves, of adopters. Information on tribal RAPs as of October 2009 is from the BIA. The list includes120 federally recognized tribes, with approval dates spanning between 1993 and September 2008. We match these RAP tribes with a list of 2010 gaming nations as reported by the National Indian Gaming Commission (NIGC, 2010) and merge these materials with the Taylor and Kalt (2005) data. The census information is tribal-level data collected as part of the 1990 and 2000 decennial censuses and currently offers the most comprehensive coverage of Native American tribes spanning the American states. Taylor and Kalt also report the gaming status of nations during the 1990s, which we supplement with other sources about the earlier decade (AGA, 1999, 2000; McQueen, 2000). After eliminating 20 tribes with no census information, the data set developed by Taylor and Kalt provides 330 cases representing all remaining nations located in the contiguous American states.

Out of these 330 cases, we retain 210 for analysis, all of which established various forms of Class III gaming activities under the IGRA sometime during either the 1990s or 2000s, including 53 tribes (25.2\%) that joined the gaming ranks during the 2000s. Although Meister (2009) only releases aggregate information, 210 represents almost $92 \%$ of the Class III tribes he reports in 2008; virtually all of the remaining cases were non-gaming. These 210 gaming nations account for 101 of the 120 RAPs on file with the BIA, with 49 having a plan approved between 1993 and 2000. This represents the first wave of adopters, falling as best as we can determine, under the first regulations governing the approval of RAPs (Department of Interior, 1992). In 2000, a new set of regulations appear in the Federal Register (Department of Interior 25 C.F.R. 290). Between 2001 and 2008, the other 52 tribes received approval of a RAP. As of 2009, the 210 cases represent 17 states with at least one RAP nation with Class III gaming and eight states with Class III gaming but with no tribes adopting allocation plans.

\subsection{Independent Variables}

We compute the independent variables using aggregate tribal-level data as reported by Taylor and Kalt (2005). ${ }^{2}$ A brief description of these measures appears in Table 1. With the exception of the last one, these variables are standard measures associated with the general population survey and provide a simple snapshot of economic and social conditions in Indian communities at the beginning of 1990 and 2000. ${ }^{3}$ These measures are for Indians only, as opposed to all residents of tribal lands, since we assume this is of greater relevance to tribes as they evaluate the decision to make payments to their members.

(Table 1 about here) 
This is the author's version of a work that was accepted for publication in The Social Science Journal. Changes resulting from the publishing process, such as peer review, editing, corrections, structural formatting, and other quality control mechanisms may not be reflected in this document. Changes may have been made to this work since it was submitted for publication. A definitive version was subsequently published in The Social Science Journal, available online 16 February 2013. DOI: 10.1016/j.soscij.2013.01.002

We also include a control variable for the number of years a tribe has had a gaming compact with a state, which is an IGRA requirement tribes must satisfy prior to opening a Class III gaming facility. To determine the number of years since a tribe signed their first gaming compact we use the NIGC's (2012) gaming compacts list, supplemented with official state gaming websites and local newspapers for missing cases. We then calculate the number of years of Class III gaming by subtracting the year a tribe signed its first compact from the corresponding decade. ${ }^{4}$ Although an alternative measure is not available, there are limitations to using compacts as a measure of duration as some tribes operated illegal Class III gaming facilities for several years prior to signing a gaming compact, as is the case for a number of tribes in California (Light and Rand, 2005). Moreover, tribes do not necessarily open a casino after signing a compact. If they do, it may happen one or several years after signing and their relative success is not public. These problems are unsolvable until additional tribal-level data becomes available.

A couple of comments regarding the census data in Table 1 are in order. As Taylor and Kalt (2005) emphasize, the conditions found in Indian communities fall short of national averages at the beginning of both decades, though improvements are evident across the two time points. A second observation is the variability across variables as measured by standard deviations; the presence of extreme cases skews some of the distributions. ${ }^{5}$ For most variables, standard deviations are almost as large or are larger than the mean, suggesting a considerable amount of diversity across nations, variability that does not diminish with the omission of outliers. Not surprising is the fact that the average length of time tribes in the United States have had gaming increases dramatically from the 1990s to the 2000s as gaming markets began to mature. The conditions found in Indian Country are far from being uniform.

\subsection{Analysis}

We treat RAP adoption as a binary variable and use multivariate logistic regression to examine relative variable importance in influencing the probability of adoption in each decade. 6 Hence, we use the 1990 census data to compare nations adopting allocation plans between 1993 and $2000(n=49)$ relative to all the other gaming nations during that period $(\mathrm{n}=108){ }^{7} \quad$ Similarly, the second comparison uses the 2000 data, where we examine plan adopters during the second decade $(n=52)$ relative to the remaining gaming nations $(n=109)$, which excludes the first group of RAP adopters. Although lacking temporal precision, this design introduces the ability to compare the results for the two subgroups of adopters, which we might view as early and late adopters. However, due to census changes and the possibility that some tribes adopted more than one plan spanning the two time-periods, we take a cautious approach in this regard. ${ }^{8}$ It is also the case that our measures represent two slightly different environments relative to gaming under the IGRA. The 1990 data are pre-gaming essentially, while the 2000 data reflects possible gaming effects on tribal conditions (Taylor and Kalt, 2005), an issue we investigate as part of the analysis.

\section{Results}

A preliminary analysis of bivariate relationships (results not shown in tabular form) suggests support for all of the hypotheses. Consequently, the multivariate analysis considers all four independent variables: (1) per capita income, (2) population, (3) college graduates, and (4) the number of compact years. ${ }^{9}$ We present the results for each decade in Table $2 .^{10}$

(Table 2 about here)

The unrestricted model performs reasonably well for the first decade of adoptions, where three of the four estimates are significant at the 0.10 level. Adopting tribes are more likely to have higher incomes, smaller populations and lower percentages of college graduates. When considering the odds ratio, for every $\$ 1,000$ increase in per capita income, the odds of a tribe adopting a RAP increase by 14\%. On the other hand, for a one-unit increase in logged population, the odds of adopting a RAP decrease by more than $30 \%$. The impact of education is also important with a one percent increase in the percent of college graduates translating to a six percent decrease in the likelihood of adopting a RAP. The number of years with gaming is the only variable that does not help in understanding adoptions. Overall, this model correctly classifies $76 \%$ of the cases, which is a modest improvement relative to predictions based on the modal category. 
This is the author's version of a work that was accepted for publication in The Social Science Journal. Changes resulting from the publishing process, such as peer review, editing, corrections, structural formatting, and other quality control mechanisms may not be reflected in this document. Changes may have been made to this work since it was submitted for publication. A definitive version was subsequently published in The Social Science Journal, available online 16 February 2013. DOI: 10.1016/j.soscij.2013.01.002

Conversely, when examining the second wave of approved RAPs during the 2000s, the performance of the model drops-off considerably. Out of the four independent variables, population is the only one that is significant; smaller nations were once again more likely to adopt a RAP. This full model provides support for the relevance of population in understanding RAP adoptions, with a 59\% decrease in the odds of adopting a RAP in the 2000s for every one-unit increase in (logged) population. Not surprisingly, the equation is only able to classify $67 \%$ of the cases correctly, a slight improvement compared to predictions based on the modal frequency. For the second group of adopters there are dynamics in play we are not capturing in the present analysis.

A confounding factor in the analysis of the second wave of adopters concerns when they started gaming. The census data from the beginning of each decade represent two different environments with respect to Indian gaming. The data for 1990, as Taylor and Kalt (2005) discuss, capture the moment before the rapid expansion of national Indian gaming activities. The 2000 socio-economic characteristics, on the other hand, reflect conditions influenced by gaming's impact for tribes adopting gaming during the 1990s, which represents roughly $75 \%$ of the cases in the second wave. If gaming is having differential effects on tribal socio-economic conditions, the 2000 measures will reflect this for nations that adopted gaming in the 1990s (Conner and Taggart 2009, 2013; Taylor and Kalt, 2005). Concurrently, for tribes that joined the gaming ranks during the second decade, the 2000 data reflect a pre-gaming environment, much like the 1990 data for the first wave of RAP adopters. Hence, the 2000 measures are for one of two different conditions depending on when a nation began Class III gaming activities.

In an effort to address this issue and better understand RAP adoptions in the 2000s, we consider the gaming tribes that did not adopt a RAP in the 1990s by breaking them into two subgroups depending on the decade when gaming began. The larger subgroup $(n=105)$ includes nations that started gaming in the 1990s, 30 of whom adopted a RAP as part of the second wave. The remaining 53 tribes adopted gaming during the second decade, 22 of whom later adopted a RAP. For these two subgroups, we repeat the multivariate analysis to examine differences between the two groups. We expect the smaller subgroup to parallel patterns detected for the first wave of RAP adopters. For the larger group representing nations with Class III since the 1990s, the 2000 data reflect the impact of gaming on these conditions. These conditions may be less relevant for later RAP adopters, with improved economic conditions and greater educational gains realized due to gaming. ${ }^{11}$ We summarize these results in Table 3 , where only population explains RAP adoptions for either group. ${ }^{12}$ For tribes that adopted gaming in the 1990s and later adopters in the 2000s, both were less likely to adopt a RAP for every unit increase in population but no other predictors are significant. The findings in Table 2 for second wave RAP adopters are not a product of comingling the gaming nations from both decades.

(Table 3 about here)

\section{Conclusion}

This investigation sheds light on a relatively unexplored area of Indian gaming, and offers some support for our original expectations concerning how various tribal features influence the adoption of revenue allocation plans by gaming nations. In looking at the first wave of adopters in the 1990s, the picture appears rather complex, with the multivariate analysis suggesting several pre-existing factors appear to be in play, including income, population and education. In the second wave, population is the only factor having an appreciable impact on adoption, regardless of the decade when a tribe adopted gaming. Given the controversy that surrounds such policies, our knowledge of the approval of RAPs, how they work, and the implications they have for the overall quality of life of tribal members is woefully incomplete. The present analysis is a first step towards filling the gap in our understanding of this particular aspect of Indian gaming and the impact that tribal socioeconomic conditions have on policy adoption. 
This is the author's version of a work that was accepted for publication in The Social Science Journal. Changes resulting from the publishing process, such as peer review, editing, corrections, structural formatting, and other quality control mechanisms may not be reflected in this document. Changes may have been made to this work since it was submitted for publication. A definitive version was subsequently published in The Social Science Journal, available online 16 February 2013. DOI: 10.1016/j.soscij.2013.01.002

\section{Notes}

${ }^{1}$ The BIA provided a list of nations with a RAP and the date of Interior Department approval via email correspondence (October 15, 2009). This data is available upon request.

${ }^{2}$ There are eight tribes where population is missing in 1990 and four others in 2000 . We include these cases in the subsequent analysis as valid values and decade permit.

${ }^{3}$ We also evaluated the impact of unemployment and family poverty on adoptions, both correlated noticeably with per capita income. The results are similar but attenuated when either is employed in lieu of income but the equations are unstable when one or both are included with income. Our assessment also considered several other tribal characteristics including urbanization, percent non-Indian, percent of individuals living in crowded homes, child poverty, and high school dropout rate, which were either correlated with one of the other independent variables or unrelated to adoption.

${ }^{4}$ Thus, for tribes adopting gaming in the 1990s (the first decade in our analysis), we subtract the year they signed a gaming compact from 2000. For example, a tribe signing a compact in 1993 we code as having legalized Class III gaming (regardless of whether they have an operating casino or not) for 7 years in the first decade of our analysis. For the second decade, we subtract the compact year from 2008 (the last year of available RAP data).

${ }^{5}$ The best example of this concerns per capita income, where three tribes have per capita incomes greater than $\$ 50,000$ in 2000 , which was considerably higher than their incomes in 1990 . When excluding these cases, the standard deviation decreases from $\$ 14,606$ to $\$ 5,448$ in 2000 . All three tribes adopted Class III gaming in the 1990s, and two adopted a RAP in the same decade, while the third adopted one the next decade. Although the first two do not pose a problem because we drop them when examining the second wave of RAP adoptions, the remaining case is an influential outlier, though it has minimal impact on the multivariate results. On a more general level, we are sensitive to the possibility of a few cases skewing our results but detect no problems in this regard. Although it is not possible to verify, this case suggests that some nations have had more than one plan; it is difficult to imagine a tribe with a six figure per capita income, which is true of this case in 2000, without making payments to their members.

${ }^{6}$ Upon examining the residuals for the models we discuss herein, we report robust standard errors in light of the non-random nature of the error terms at higher levels of the independent variables. To evaluate the predictive power and overall fit of the different models, we use the percent of cases correctly classified as well as the likelihood ratio and Wald test. Variation explained, the idea behind R-squared, is not relevant in logistic regression, though a large number of pseudo measures are available. When considering six options for the results in Table 2, for instance, the values range between 0.10 and 0.76 , with an average of 0.23 . We report Cragg \& Uhler's R-squared statistic, which tends to fall around the average value of the six options.

${ }^{7}$ Sixteen tribes that adopted Class III gaming in the late 1990s had adopted RAPs prior to signing a compact in our dataset (suggesting that these tribes adopted RAPs while operating Class II casinos). All but four of these tribes are in California, where there was a difficult and prolonged legal battle surrounding casino-style gaming throughout the decade that eventually led to the adoption of Class III gaming in 1999. The inclusion of a control variable for California tribes in the multivariate models was insignificant. Dropping these 16 cases, another option examined, results in the loss of roughly one-fourth of RAP adopters in our analysis and greatly affects the results.

${ }^{8}$ It is for these reasons we do not pool the data for analysis. Another argument against pooling is due to differences in RAP regulations that changed at the beginning of the second decade that may have appreciable effects on both the pursuit and approval of payment plans. The estimation of a pooled model, with a dummy variable for gaming decade, generates results largely consistent with what we report but obscures the differential findings by decade.

${ }^{9}$ Given the measurement scales and distributional skewness, we convert per capita income to 1,000s and population to the base-10 logarithm.

${ }^{10}$ A test of multicollinearity for both models reveals little reason for concern; the tolerance measures range from 0.84 to 0.94 and 0.68 to 0.92 , respectively. Given the non-random nature of the data (based on population and not a sample), a test of statistical significance is not appropriate but helps to detect relationships suggesting greater impacts. Furthermore, while three of our variables have expected relationships with RAP adoption, which would imply a one-tail test of significance, we use a more stringent two-tail test, making it harder to reject the null.

${ }^{11}$ Given the lackluster performance of the year variable in Table 2 and the grouping of tribes by decade of gaming's adoption, we exclude the number of compact years.

${ }^{12}$ Part of the reason why several of the important variables failed to achieve statistical significance in the logistic regression models is the small number of cases for both sets of analyses when censoring the data. 
This is the author's version of a work that was accepted for publication in The Social Science Journal. Changes resulting from the publishing process, such as peer review, editing, corrections, structural formatting, and other quality control mechanisms may not be reflected in this document. Changes may have been made to this work since it was submitted for publication. A definitive version was subsequently published in The Social Science Journal, available online 16 February 2013. DOI: 10.1016/j.soscij.2013.01.002

\section{References}

American Gaming Association (AGA). (2010). Industry Information: Fact Sheets. February 21.

Available at $<$ http://www.americangaming.org $>$.

. (2009). State of the States: The AGA Survey of Casino Entertainment. June21.

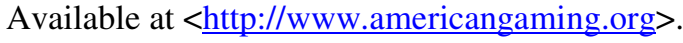

(2000). State Information: Statistics. Available at

$<$ http://www.americangaming.org $>$.

(1999). State Information: Statistics. Available at

<http://www.americangaming.org $>$.

Bartlett, D. L. \& Steele, J. B. (2002). Special Report Indian Casinos: Wheel of Misfortune. Time Magazine. December 16: 44-58.

Berry, F. S. \& Berry, W. D. (2007). Innovation and Diffusion Models in Policy Research. In P. Sabatier (Eds.), Theories of the Policy Process. Boulder, CO: Westview Press, 223-260.

. (1990). State Lottery Adoptions as Policy Innovations: An Event History Analysis.

American Political Science Review, 84(2), 395-415.

Conner, T. W. \& Taggart, W. A. (2012). Assessing the Impact of Indian Gaming on American Indian Nations: Is the House Winning. Social Science Quarterly, forthcoming.

. (2009). A Comparative Analysis of the Impact of Indian Gaming

on New Mexico's Tribes and Pueblos. Social Science Quarterly, 90(1), 50-70.

Department of Interior. (1992). Guidelines to Govern the Review and Approval of Per Capita Distribution Plans. U.S. Department of Interior, December 21, 1992.

Department of Interior. (1988). 25 CFR 290: Tribal Revenue Allocation Plans. Available at <http://www.nigc.gov/Portals/0/NIGC\%20Uploads/lawsregulations/DOI\%20Gaming\%20Regulations/DOI \%20part\%20290.pdf>.

Furlong, E. J. (1998). A Logistic Regression Model Explaining Recent Casino Gaming Adoptions. Policy Studies Journal, 26(3), 371-383.

Gray, V. (1973). Innovation in the States: A Diffusion Study. American Political Science Review, 67(4), 1174-1185.

Grossback, L.,, Nicholson-Crotty, S., \& Peterson, D. (2004). Ideology and Learning in Policy Diffusion. American Politics Research, 32(5), 521-545.

Indian Gaming Regulatory Act of 1988 (IGRA), 102 U.S. Statute 2467.

Krepps, M.B., Taylor, J. B., \& Bucks, B.K. (1998).Untangling the Determinants of Casino Authorization: An Analysis of State-Tribal Casino Compacting. Gaming Law Review, 2(6), 657-665.

Light, S.A.\& Rand, K. R. L. (2005). Indian Gaming and Tribal Sovereignty: The Casino Compromise. Lawrence, KS: University Press of Kansas.

Meister, Alan. (2010). Casino City’s Indian Gaming Industry Report: 2010-2011 Edition. Newton, MA: Casino City Press. 
This is the author's version of a work that was accepted for publication in The Social Science Journal. Changes resulting from the publishing process, such as peer review, editing, corrections, structural formatting, and other quality control mechanisms may not be reflected in this document. Changes may have been made to this work since it was submitted for publication. A definitive version was subsequently published in The Social Science Journal, available online 16 February 2013. DOI: 10.1016/j.soscij.2013.01.002

McQueen, P. (2000). United States Gaming at a Glance. International Gaming and Wagering Business, November, 21.

Morse, E. A. \& Goss, E. P. (2007). Governing Fortune: Casino Gambling in America. Ann Arbor, MI: University of Michigan Press.

National Gambling Impact Study Commission (NGISC). (1999). Final Report. Washington, D.C.: NGISC. Available at <http://govinfo.library.unt.edu/ngisc/reports/fullrpt.html>.

National Indian Gaming Association (NIGA). (2011). The Economic Impact of Indian Gaming. Available at < http://www.indiangaming.org $>$.

National Indian Gaming Commission (NIGC). (2012). Reading Room: Compacts. Available at <http://www.nigc.gov/Reading_Room/Compacts.aspx>.

(NIGC). (2010). Gaming Tribe Report: Sorted Alphabetically August 11, 2010. Available at <www.nigc.gov $>$.

Rand, K. R. L. \& Light, S. A. (1997). Virtue or Vice? How the IGRA Shapes the Politics of Native American Gaming, Sovereignty, and Identity. Virginia Journal of Social Policy and the Law, 4(2), 381-437.

Schaap, J.I. (2010). The Growth of the Native American Gaming Industry: What has the Past Provided, and What does the Future Hold? American Indian Quarterly, 34(3): 365-389.

Smith, W. G. \& Taggart, W. A. (2010). Tribal-State Gaming Compacts 20 Years after Passage of the Indian Gaming Regulatory Act. Gaming Law Review and Economics, 14(2), 85-90.

Taggart, W. A. \& Conner, T. W. (2011). Indian Gaming and Tribal Revenue Allocation Plans: A Case of Play to Pay. Gaming Law Review and Economics, 15(6), 355-363.

Taylor, J.B. \& Kalt, J. (2005). American Indians on Reservations: A Databook of Socioeconomic Change between the 1990 and 2000 Censuses. January. The Harvard Project on American Indian Economic Development. Available at <http://www.ksg.harvard.edu/hpaied/>.

Winn, B. M. \& Whicker, M. L. (1990). Indicators of State Lottery Adoptions. Policy Studies Journal, 18(2), 293304.

Witmer, Richard and Frederick J. Boehmke. (2007). American Indian Political Incorporation in the Post-Indian Gaming Regulatory Act Era. The Social Science Journal, 44, 127-145. 
This is the author's version of a work that was accepted for publication in The Social Science Journal. Changes resulting from the publishing process, such as peer review, editing, corrections, structural formatting, and other quality control mechanisms may not be reflected in this document. Changes may have been made to this work since it was submitted for publication. A definitive version was subsequently published in The Social Science Journal, available online 16 February 2013. DOI: 10.1016/j.soscij.2013.01.002

Table 1

Independent Variables with Descriptive Statistics and Expected Relationship with RAP Adoption ${ }^{1}$

\begin{tabular}{l|lll}
\hline Independent Variables & $\begin{array}{l}\text { 1990 Mean/Standard } \\
\text { Deviation/ }(n)\end{array}$ & $\begin{array}{l}\text { 2000 Mean/Standard } \\
\text { Deviation/ }(n)\end{array}$ & $\begin{array}{l}\text { Hypothesized } \\
\text { Relationship }\end{array}$ \\
\hline \multirow{3}{*}{ 1. Per capita income } & $\$ 8,020.85 /$ & $\$ 12,606.85 /$ & Positive \\
& $\$ 4,293.74 /(202)$ & $\$ 14,605.88 /(205)$ & \\
2. Population & $2028.40 /$ & $2351.46 /$ & Negative \\
& $6312.08 /(202)$ & $6937.47 /(206)$ & \\
3. $\%$ college graduate & $9.53 /$ & $11.41 /$ & Negative \\
& $7.63 /(196)$ & $8.12 /(206)$ & \\
4. Number of years with & $4.53 /$ & $11.58 /$ & Unclear \\
gaming compact & $3.31 /(183)$ & $4.16 /(206)$ & \\
\hline
\end{tabular}

${ }^{1}$ Source: Taylor and Kalt (2005) and NIGC (2012). 
This is the author's version of a work that was accepted for publication in The Social Science Journal. Changes resulting from the publishing process, such as peer review, editing, corrections, structural formatting, and other quality control mechanisms may not be reflected in this document. Changes may have been made to this work since it was submitted for publication. A definitive version was subsequently published in The Social Science Journal, available online 16 February 2013. DOI: 10.1016/j.soscij.2013.01.002

Table 2

Logistic Analysis of RAP Adoptions in the 1990s and 2000s ${ }^{1}$

\begin{tabular}{|c|c|c|c|c|}
\hline & \multicolumn{2}{|c|}{ RAP Adoption 1990s } & \multicolumn{2}{|c|}{ RAP Adoption 2000s } \\
\hline $\mathrm{DV}=\mathrm{RAP}$ Adoption & Coef. & $\begin{array}{l}\text { Odds } \\
\text { Ratio }\end{array}$ & Coef. & $\begin{array}{l}\text { Odds } \\
\text { Ratio }\end{array}$ \\
\hline Per capita income (in 1,000 s) & $\begin{array}{l}.127 \wedge \\
(.078)\end{array}$ & 1.135 & $\begin{array}{l}.021 \\
(.024)\end{array}$ & 1.021 \\
\hline Population (log base 10$)$ & $\begin{array}{l}-.421^{\wedge} \\
(.239)\end{array}$ & .657 & $\begin{array}{c}-.894 * * \\
(.263)\end{array}$ & .409 \\
\hline$\%$ college graduates & $\begin{array}{l}-.058^{\wedge} \\
(.033)\end{array}$ & .944 & $\begin{array}{l}-.011 \\
(.023)\end{array}$ & .989 \\
\hline $\begin{array}{l}\text { Number of years with } \\
\text { gaming compact }\end{array}$ & $\begin{array}{l}.055 \\
(.063)\end{array}$ & 1.057 & $\begin{array}{l}-.027 \\
(.047)\end{array}$ & .974 \\
\hline Constant & $\begin{array}{l}-.696 \\
(.884)\end{array}$ & & $\begin{array}{l}1.866^{*} \\
(.821)\end{array}$ & \\
\hline $\begin{array}{l}\text { Number of observations } \\
\text { Wald chi }{ }^{2}(4) \\
\text { Log-Likelihood } \\
\text { Cragg \& Uhler's } \mathrm{R}^{2} \\
\text { Pearson chi } \\
\text { Hosmer-Lemeshow } \\
\text { Cases predicted correctly }\end{array}$ & $\begin{array}{c}144 \\
17.61 * * \\
-78.44 \\
0.16 \\
141.55 \\
15.15^{\wedge} \\
76 \%\end{array}$ & & $\begin{array}{c}156 \\
19.91 * * \\
-87.12 \\
0.19 \\
147.54 \\
10.14 \\
67 \%\end{array}$ & \\
\hline
\end{tabular}

\footnotetext{
$\wedge p<0.10, * p<0.05$, and $* * p<0.01$, two-tail test.
}

${ }^{1}$ Robust standard errors in parentheses. 
This is the author's version of a work that was accepted for publication in The Social Science Journal. Changes resulting from the publishing process, such as peer review, editing, corrections, structural formatting, and other quality control mechanisms may not be reflected in this document. Changes may have been made to this work since it was submitted for publication. A definitive version was subsequently published in The Social Science Journal, available online 16 February 2013. DOI: 10.1016/j.soscij.2013.01.002

\section{Table 3}

Logistic Analysis of RAP Adoptions in the 2000s by Decade of Gaming Adoption ${ }^{1}$

\begin{tabular}{|c|c|c|c|c|}
\hline & \multicolumn{2}{|c|}{$\begin{array}{l}\text { Class III Gaming } \\
\text { in } 1990 \mathrm{~s}\end{array}$} & \multicolumn{2}{|c|}{$\begin{array}{l}\text { Class III Gaming } \\
\quad \text { in } 2000 \mathrm{~s}\end{array}$} \\
\hline & Coef. & $\begin{array}{l}\text { Odds } \\
\text { Ratio }\end{array}$ & Coef. & $\begin{array}{l}\text { Odds } \\
\text { Ratio }\end{array}$ \\
\hline Per capita income (in 1,000 s) & $\begin{array}{c}.076 \\
(.069)\end{array}$ & 1.021 & $\begin{array}{l}-.178 \\
(.116)\end{array}$ & .837 \\
\hline Population (log base 10) & $\begin{array}{c}-.919 * * \\
(.374)\end{array}$ & .409 & $\begin{array}{c}-1.066^{*} \\
(.483)\end{array}$ & .344 \\
\hline$\%$ college graduates & $\begin{array}{l}-.047 \\
(.031)\end{array}$ & .989 & $\begin{array}{l}-.046 \\
(.042)\end{array}$ & 1.047 \\
\hline Constant & $\begin{array}{c}1.292 \\
(.1 .237)\end{array}$ & & $\begin{array}{l}3.587^{\wedge} \\
(1.928)\end{array}$ & \\
\hline $\begin{array}{l}\text { Number of observations } \\
\text { Wald chi }{ }^{2}(4) \\
\text { Log-Likelihood } \\
\text { Cragg \& Uhler's } \mathrm{R}^{2} \\
\text { Pearson chi } \\
\text { Hosmer-Lemeshow } \\
\text { Cases predicted correctly }\end{array}$ & $\begin{array}{c}105 \\
9.02 * \\
-52.16 \\
0.24 \\
96.36 \\
10.38 \\
74 \%\end{array}$ & & $\begin{array}{c}53 \\
5.05 \\
-31.53 \\
0.21 \\
54.06 \\
10.79 \\
72 \%\end{array}$ & \\
\hline
\end{tabular}

$\hat{\wedge} p<0.10, * p<0.05$, and $* * p<0.01$, two-tail test.

${ }^{1}$ Robust standard errors in parentheses. 